\title{
O PROCESSO DECISÓRIO DE COMPRA DO CONSUMIDOR EM UMA LOJA DE ROUPAS CASUAIS
}

\author{
THE CONSUMER PURCHASE DECISION PROCESS IN \\ A CASUAL CLOTHING STORE
}

Jéssika Lamartine de Souza ${ }^{\mathrm{I}}$

Gustavo Barbieri Lima ${ }^{\text {II }}$

\begin{abstract}
RESUMO
O objetivo central da presente pesquisa é compreender o comportamento de compra de consumidoras de uma loja de roupas casuais, localizada no interior do estado de Minas Gerais, assim como investigar o nível de satisfação das clientes com a loja (localização, infraestrutura, atendimento etc.). Esta pesquisa caracteriza-se como qualitativa, de natureza exploratória. Para o desenvolvimento da mesma, realizaram-se 06 entrevistas com clientes da referida loja, seguindo-se um roteiro de entrevista semiestruturado, contendo 19 questões. Os principais resultados apontam que: as consumidoras entrevistadas seguem os perfis de lojas para acompanhar o que está na moda e o que tem sido usado, mas não seguem exatamente as últimas tendências, comprando de acordo com o que gostam e suas necessidades; todas as entrevistadas valorizam a comodidade das compras pela internet, mas a maioria ainda prefere a compra na loja física, o que não deixa de ser muito importante estar presente nas redes sociais, acompanhado o que está acontecendo e também postando as novidades, uma vez que as consumidoras têm o hábito de visualizar as roupas divulgadas na Internet e ir até a loja para experimentar e comprar; na maioria das respostas, as compras de roupas e acessórios acontecem por impulso e muitas vezes as consumidoras não vão às compras com um modelo pré-definido; em relação às perguntas específicas sobre a loja, as consumidoras gostam muito do estilo de roupa oferecido e as consideram lindas, mas não inovadoras e diferenciadas; um estilo mais básico e casual.
\end{abstract}

Palavras-chave: Comportamento do consumidor. Consumo. Varejo. Segmento de moda.

\begin{abstract}
The central objetive of this research is to understand the buying behavior of consumers of a casual clothing store, located in the countryside of the state of Minas Gerais, as well as to investigate the level of customer satisfaction with the store (location, infrastructure, service etc.). This research is characterized as qualitative, of exploratory nature. For its development, 06 interviews were conducted with customers of the store, following a semi-structured interview script containing 19 questions. The main results indicate that the interviewed consumers follow the store profiles to follow what is in fashion and what has been used, but they do not follow exactly the latest trends, buying according to what they like and their needs; all the interviewees value the convenience of internet shopping, but most still prefer to buy in the physical store, which is still very important to be present on social networks,

\footnotetext{
I Estudante do Curso de MBA em Marketing - PECEGE/ ESALQ - Universidade de São Paulo - Piracicaba S.P. - Brasil. E-mail: jessikalamartine@hotmail.com

II Prof. Ms. do PECEGE/ ESALQ - Universidade de São Paulo - Piracicaba - S.P. - Brasil. E-mail: barbieri.lima@yahoo.com.br
} 
following what is happening and also posting the news, since the consumers have the habit of viewing the clothes advertised on the internet and go to the store to try on and buy; in most responses, the purchases of clothes and accessories happen on impulse and often consumers do not go shopping with a pre-defined model; regarding the specific questions about the store, consumers really like the style of clothes offered and consider them beautiful, but not innovative and differentiated; a more basic and casual style.

Keywords: Consumer behavior. Consumption. Retail. Fashion segment.

Data de submissão do artigo: 17/06/2021.

Data de aprovação do artigo: 10/08/2021.

DOI: $10.33635 /$ sitefa.v4i1.165

\section{INTRODUÇÃO}

A busca das empresas em estudar o comportamento do consumidor surgiu a partir de uma percepção da importância de construir uma ligação entre colaboradores (representantes da organização) e os consumidores finais objetivando a criação de um vínculo, assim interferindo no seu processo decisório de compra. Para que a empresa possa de fato influenciar a decisão de compra do consumidor é necessário que ela conheça os motivos que exercem influência em suas decisões e entender que para o cliente o produto isolado não é o principal, e sim todo o processo decisório de compra realizado pela empresa que envolve a venda do produto e/ou serviço desde o seu primeiro estágio até o pós-venda. Isso faz com que a empresa se torne mais competitiva e com importante diferencial em um mercado altamente dinâmico.

É indispensável para as empresas obterem o maior número de informações relevantes sobre o comportamento de seus clientes, pois eles não procuram somente o produto e/ou serviço de uma maneira isolada. Eles tendem a optar por empresas que aliem "o que eles buscam" com a praticidade que o mercado atualmente exige, gerando um tipo de diferencial e um valor a mais para o cliente.

A escolha de uma empresa no ramo de vestuário feminino se deu pelo constante crescimento, alto índice de competitividade e por ser um mercado incrivelmente dinâmico em que posicionar-se de maneira efetiva e clara só traz benefícios para a organização, pois deixa clara a sua intenção, objetivos e torna mais próxima a identificação do consumidor final, aproximando suas relações. Através dos conhecimentos adquiridos em relação ao tema abordado, as empresas conseguem implantar medidas necessárias para a melhoria na sua atuação.

Assim sendo, o objetivo central da presente pesquisa é compreender o comportamento de compra de consumidoras de uma loja de roupas casuais, localizada no interior do estado de Minas Gerais, assim como investigar o nível de satisfação das clientes com a loja (localização, infraestrutura, atendimento etc.).

\section{ETAPAS DO PROCESSO DECISÓRIO DE COMPRA}

O processo decisório de compra do consumidor inclui cinco etapas: reconhecimento do problema, busca de informações, avaliação das alternativas, decisão de compra e avaliação pós compra.

Na Figura 1 é mostrado sequencialmente este modelo. 


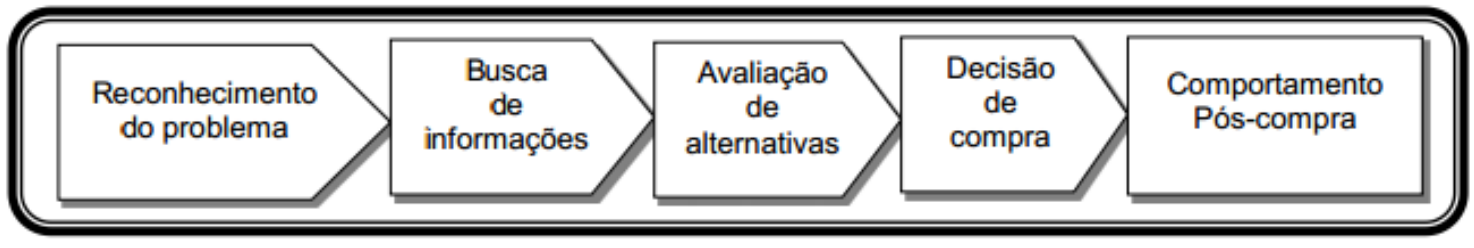

Fonte: Kotler e Keller (2006, p.189)

O reconhecimento do problema é a fase em que o consumidor sente uma necessidade de comprar um produto ou serviço. "Quando os consumidores percebem que têm uma necessidade, o impulso interior para atendê-la é chamado motivação" (CHURCHILL, 2000, p. 147). Por isso é de suma importância para os profissionais saberem o que motiva seus clientes, para que consigam atender suas vontades e desejos. Em alguns casos as estratégias de marketing impulsionam o consumidor a reconhecer uma necessidade, por meios de estímulos que façam com que os consumidores sintam o desejo de adquirir determinado produto ou serviço.

O segundo estágio é a busca por informações, que os consumidores realizam para satisfazer as necessidades que foram identificadas. Kotler e Keller (2006) mostram que a busca por informações acontece em dois níveis: a atenção elevada, onde o consumidor é mais receptivo às informações que lhes são passadas, buscam também informações entre amigos, parentes, propagandas, e a busca ativa de informações em que o cliente pesquisa mais intensamente sobre os produtos ou serviços de seu interesse, realizando pesquisas sobre preço, qualidade, procurando sempre o que melhor vai atendê-lo.

Para Sheth, Mittal e Newman (2001, p. 490) "a busca por informações acontece em três fases, fontes de informação, estratégias de busca e quantidade de busca." As fontes de informações são divididas em empresariais e não empresarias. As empresariais são fornecidas pelas empresas que estão oferecendo os produtos ou serviços. Elas fazem propagandas, brochuras, entre outras formas de divulgação. São conhecidas como fontes interessadas, por as empresas disponibilizarem informações sempre favoráveis. As fontes não empresariais independem da empresa. São as experiências anteriores dos consumidores, a busca por informações em meios que não são manipulados pelas mesmas, opiniões de outros clientes disponíveis na internet. As estratégias de busca são o meio em que os clientes irão adquirir as informações necessárias para o processo decisório de compra de uma maneira mais rápida e eficaz. A quantidade de busca é a determinante sobre quantas informações o consumidor precisará buscar. É necessário avaliar o risco percebido, que é o quanto o cliente irá perder se fizer uma escolha errada, o envolvimento que define o cuidado que os consumidores têm no processo de compra e a importância percebida do produto ou serviço, a familiaridade e perícia em virtude de uma experiência anterior, a pressão de tempo, pois cada vez mais clientes estão buscando lugares mais convenientes para realizarem suas compras. Depois de assimilarem as informações, os consumidores analisam as formas de satisfazer seus desejos e necessidades. Essas avaliações definem o que é importante para o cliente, o que irá lhe proporcionar maior valor.

De acordo com Mowen e Minor (2003, p.201), "No estágio de avaliação das alternativas durante o processo decisório de compra, o consumidor compara as opções identificadas como potencialmente capazes de resolver o problema que iniciou o processo de decisão". Ao comparar as alternativas os clientes criam atitudes, intenções e crenças que resultam em uma afeição sobre as opções consideradas. Para Kotler e Keller (2006, p. 191) "não existe um modelo único para o julgamento de um valor final, pois os clientes possuem bases racionais e conscientes quando realizam a avaliação das opções."

Após realizar a avaliação das alternativas, tem-se a quarta etapa, que é a decisão de compra. É nessa etapa que o cliente decide por efetuar a compra ou não. Além de escolher entre marcas de um produto, a decisão também envolve onde comprar, quando e como pagar. 
"O processo de escolha difere em função dos consumidores usarem uma abordagem de alto envolvimento ou de baixo envolvimento" (MOWEN; MINOR, 2003, p. 202).

As escolhas de alto envolvimento referem-se à um modelo compensatório, onde os consumidores avaliam cada alternativa de uma forma amplamente avaliadora, de modo que as vantagens podem compensar as desvantagens do que se deseja adquirir. Neste modelo todas as informações sobre os atributos de uma marca são julgadas para a preferência final do consumidor.

Já as escolhas de baixo envolvimento são um modelo não compensatório, onde as vantagens de um produto ou serviço podem não compensar as desvantagens dele. Kotler e Keller (2006) destacam três regras heurísticas de escolha, que são: heurística conjuntiva, heurística lexicográfica e heurística de eliminação de aspectos. Na primeira o cliente define índices mínimos aceitáveis para cada atributo que deseja buscar. Caso o produto não se encaixe nos atributos mínimos ele será rejeitado. Na segunda heurística o consumidor realiza sua escolha através de uma qualidade percebida como mais importante. E na terceira ocorre um processo hierárquico, em que há uma comparação sobre os atributos mais importantes. Os produtos que não ultrapassam o padrão estabelecido são eliminados do processo. "As características da pessoa, a dificuldade e o ambiente da decisão de compra, e o contexto social podem afetar se/ou como as heurísticas de escolha são utilizadas." (KOTLER; KELLER, 2006, p. 195).

A última etapa do processo decisório é a avaliação pós-compra em que há uma avaliação formal ou informal dos consumidores sobre o resultado da aquisição. Eles consideram se ficaram satisfeitos ou não com o produto ou serviço adquirido. As empresas devem voltar sua atenção para sempre melhor atender os clientes, pois quando eles ficam satisfeitos além de voltarem para realizar outras compras, também passam uma boa mensagem para outras pessoas (SHETH; MITTAL; NEWMAN, 2001).

\section{PROCEDIMENTOS METODOLÓGICOS}

A presente pesquisa caracteriza-se como qualitativa, de natureza exploratória. A pesquisa qualitativa interpreta e analisa as características mais a fundo, fornecendo dados mais detalhados sobre o estudo. Segundo Collis e Hussey $(2005$, p.26) "envolve examinar e refletir as percepções para obter um entendimento de atividades sociais e humanas." Objetivando o conhecimento dos atributos que influenciam no processo decisório de compra dos consumidores.

Para Malhotra (2001, p. 155) a pesquisa qualitativa é definida como uma técnica de "pesquisa não-estruturada, exploratória, baseada em pequenas amostras, que proporciona insights e compreensão do contexto do problema" que está sendo estudado. A natureza do trabalho em questão é caracterizada por uma pesquisa exploratória, que objetiva fornecer um maior conhecimento sobre o tema proposto. É utilizada em casos nos quais é necessário definir o problema com maior precisão.

Ainda segundo Malhotra (2001, p. 106), a pesquisa exploratória "é um tipo de pesquisa que tem como principal objetivo o fornecimento de critérios sobre a situaçãoproblema enfrentada pelo pesquisador e sua compreensão".

Para o desenvolvimento deste estudo, realizaram-se 06 entrevistas em profundidade semiestruturadas, seguindo-se um roteiro de entrevista pré-definido, com clientes da referida loja, visando-se alcançar o objetivo proposto. Elaborou-se um quadro com 19 questões (primeira coluna) e com os 06 respondentes nas demais colunas. Triviños (1987, p. 146) afirma que a entrevista semiestruturada tem como característica questionamentos básicos que são apoiados em teorias e hipóteses que se relacionam ao tema da pesquisa. Sendo assim, é uma pesquisa onde não se tem a necessidade de seguir exatamente uma lista de perguntas estruturadas. 


\section{RESULTADOS E DISCUSSÃO}

O quadro 01 apresenta o resultado das 06 entrevistas em profundidade que foram realizadas com consumidoras/ clientes da loja de roupas casuais, localizada no interior do estado de Minas Gerais. 


\section{(IV) SITEFA}

Quadro 01 - Resultados das entrevistas semiestruturadas

\begin{tabular}{|c|c|c|c|c|c|c|}
\hline Questões & Entrevistado 1 & Entrevistado 2 & Entrevistado 3 & Entrevistado 4 & Entrevistado 5 & Entrevistado 6 \\
\hline $\begin{array}{l}\text { 01. Você já comprou alguma roupa que não precisava e não } \\
\text { cogitava comprar naquele momento, por ter visto na internet e } \\
\text { ter gostado? }\end{array}$ & $\begin{array}{l}\text { "Sim, mas somente } \\
\text { de lojas que já } \\
\text { conheço" }\end{array}$ & $\begin{array}{l}\text { "Várias vezes. } \\
\text { Compro muito por } \\
\text { impulso e por } \\
\text { achar bonito" }\end{array}$ & $\begin{array}{l}\text { "Sim, faço com } \\
\text { frequência. Só } \\
\text { compro roupa por } \\
\text { impulso, raramente } \\
\text { por necessidade" }\end{array}$ & $\begin{array}{l}\text { "Não, só compro } \\
\text { se tiver } \\
\text { necessidade ou } \\
\text { ocasião" }\end{array}$ & $\begin{array}{l}\text { "Muitas vezes, } \\
\text { compro por } \\
\text { impulso com muita } \\
\text { freqüencia" }\end{array}$ & $\begin{array}{l}\text { "Pela internet } \\
\text { não, apenas em } \\
\text { loja de rua" }\end{array}$ \\
\hline $\begin{array}{l}\text { 02. Se a loja deixasse de ter um local físico, você continuaria } \\
\text { comprando apenas pela internet? }\end{array}$ & $\begin{array}{l}\text { "Sim, continuo } \\
\text { cliente de algumas } \\
\text { lojas que } \\
\text { fecharam" }\end{array}$ & $\begin{array}{l}\text { "Sim, } \\
\text { principalmente se } \\
\text { já conhecer a loja" }\end{array}$ & $\begin{array}{l}\text { "Não, roupa eu } \\
\text { gosto de } \\
\text { experimentar" }\end{array}$ & $\begin{array}{l}\text { "Se eu precisar do } \\
\text { produto, sim" }\end{array}$ & $\begin{array}{l}\text { "Se eu conhecer e } \\
\text { confiar na loja e na } \\
\text { qualidade, sim" }\end{array}$ & $\begin{array}{l}\text { "Roupas não, } \\
\text { outros produtos } \\
\text { sim" }\end{array}$ \\
\hline $\begin{array}{l}\text { 03. O que você ainda não compra pela internet? Considera } \\
\text { começar a comprar em algum momento? }\end{array}$ & $\begin{array}{l}\text { "Acessórios. Não } \\
\text { pretendo comprar } \\
\text { por ser muito } \\
\text { específico" }\end{array}$ & $\begin{array}{l}\text { "Nada, tudo o que } \\
\text { preciso costumo } \\
\text { comprar na } \\
\text { internet ou loja } \\
\text { fisica" }\end{array}$ & $\begin{array}{l}\text { "Roupa. Não } \\
\text { considero começar } \\
\text { a comprar" }\end{array}$ & $\begin{array}{l}\text { "Alimentos do } \\
\text { mês. Não pretendo } \\
\text { comprar pela } \\
\text { internet" }\end{array}$ & $\begin{array}{l}\text { "Nada, hoje } \\
\text { compro tudo por } \\
\text { sites e aplicativos " }\end{array}$ & $\begin{array}{l}\text { "Não compro } \\
\text { roupas pela } \\
\text { internet. Não } \\
\text { compraria, pois } \\
\text { tenho que } \\
\text { experimentar" }\end{array}$ \\
\hline $\begin{array}{l}\text { 04. Você segue muitas lojas de roupas nas redes sociais? Realiza } \\
\text { alguma interação com os perfis? }\end{array}$ & $\begin{array}{l}\text { "Sigo muitas lojas, } \\
\text { mas não tenho } \\
\text { interação" }\end{array}$ & $\begin{array}{l}\text { "Sigo muitas lojas } \\
\text { de roupas e só } \\
\text { interajo quando } \\
\text { quero saber o } \\
\text { preço de algo" }\end{array}$ & $\begin{array}{l}\text { "Não, sigo poucas. } \\
\text { Prefiro a interação } \\
\text { física" }\end{array}$ & $\begin{array}{l}\text { "Sim, mas não } \\
\text { faço interações" }\end{array}$ & $\begin{array}{l}\text { "Sigo muitas lojas } \\
\text { e compro através } \\
\text { de várias pelas } \\
\text { redes sociais" }\end{array}$ & $\begin{array}{l}\text { "Sigo algumas e } \\
\text { não interajo" }\end{array}$ \\
\hline $\begin{array}{l}\text { 05. Para você, quais são as vantagens e desvantagens de realizar } \\
\text { a compra pela internet? E em lojas físicas? }\end{array}$ & $\begin{array}{l}\text { "Internet: poder } \\
\text { comprar sem sair } \\
\text { de casa, mas ter } \\
\text { que pagar frete e } \\
\text { não poder } \\
\text { experimentar. } \\
\text { Lojas físicas: } \\
\text { poder } \\
\text { experimentar, mas } \\
\text { ter que me } \\
\text { deslocar" }\end{array}$ & $\begin{array}{l}\text { "Praticidade da } \\
\text { internet e poder } \\
\text { comprar a } \\
\text { qualquer momento, } \\
\text { mas é ruim não } \\
\text { poder } \\
\text { experimentar. Loja } \\
\text { fisica pode } \\
\text { experimentar, mas } \\
\text { tem que ir até o } \\
\text { local" }\end{array}$ & $\begin{array}{l}\text { "Vantagem éo } \\
\text { preço e a forma de } \\
\text { pagamento, que } \\
\text { costuma ser } \\
\text { melhor. } \\
\text { Desvantagem: } \\
\text { muito trabalho } \\
\text { para devolver se } \\
\text { não gosto. } \\
\text { Lojas: posso ver e } \\
\text { pegar no produto. } \\
\text { Desvantagem: } \\
\text { divide menos, } \\
\text { gosto de dividir de } \\
10 \text { vezes" }\end{array}$ & $\begin{array}{l}\text { "Vantagem é } \\
\text { comprar sem sair } \\
\text { de casa e conforto, } \\
\text { desvantagem é } \\
\text { frete o o produto } \\
\text { não atender } \\
\text { minhas } \\
\text { expectativas. } \\
\text { Vantagem é poder } \\
\text { olhar, pegar e } \\
\text { experimentar. } \\
\text { Desvantagem o } \\
\text { tempo que } \\
\text { demanda para ir } \\
\text { até o local" } \\
\end{array}$ & $\begin{array}{l}\text { "A internet me } \\
\text { proporciona } \\
\text { conforto, mas } \\
\text { demora para } \\
\text { chegar. A loja } \\
\text { fisica saio da loja } \\
\text { com a roupa, mas } \\
\text { preciso de tempo } \\
\text { para ir até o local" }\end{array}$ & $\begin{array}{l}\text { "A vantagem da } \\
\text { internet são os } \\
\text { preços que são } \\
\text { melhores e } \\
\text { desvantagem éo } \\
\text { frete. A vantagem } \\
\text { da loja fisica e ver } \\
\text { o produto e } \\
\text { desvantagem são } \\
\text { os preços } \\
\text { maiores" }\end{array}$ \\
\hline
\end{tabular}




\begin{tabular}{|c|c|c|c|c|c|c|}
\hline $\begin{array}{l}\text { 06. O que você costuma comprar em uma loja de roupas } \\
\text { feminina? Leva mais de um tipo de roupas e acessórios? }\end{array}$ & $\begin{array}{l}\text { "Blusas, vestidos, } \\
\text { shorts. Levo várias } \\
\text { coisas, inclusive } \\
\text { acessórios" }\end{array}$ & $\begin{array}{l}\text { "Todos os tipos de } \\
\text { roupas e } \\
\text { acessórios. Só não } \\
\text { compro sapatos" }\end{array}$ & $\begin{array}{l}\text { "Vestido, calça, } \\
\text { blusa, macacão. Só } \\
\text { não compro saia" }\end{array}$ & $\begin{array}{l}\text { "Roupas para sair } \\
\text { e trabalhar" }\end{array}$ & "Compro de tudo" & $\begin{array}{l}\text { "Compro de tudo, } \\
\text { mas só levo um } \\
\text { tipo de roupa de } \\
\text { cada vez" }\end{array}$ \\
\hline $\begin{array}{l}\text { 07. Você tem o hábito de ver uma roupa que gosta nas redes } \\
\text { sociais de lojas de roupas e ir experimentar na loja física? }\end{array}$ & $\begin{array}{l}\text { "Sim, mas não com } \\
\text { muita frequência" }\end{array}$ & $\begin{array}{l}\text { "Já aconteceu } \\
\text { várias vezes, mas } \\
\text { quando a loja é de } \\
\text { fácil acesso" }\end{array}$ & $\begin{array}{l}\text { "Já fiz isso } \\
\text { algumas vezes" }\end{array}$ & $\begin{array}{l}\text { "Não, não olho o } \\
\text { que não vou } \\
\text { comprar" }\end{array}$ & $\begin{array}{l}\text { "Se a loja for de } \\
\text { fácil acesso, sim" }\end{array}$ & $\begin{array}{l}\text { "Pouquíssimo. } \\
\text { Raramente } \\
\text { acontece" }\end{array}$ \\
\hline $\begin{array}{l}\text { 08. Quais decisões você toma antes de realizar uma compra por } \\
\text { internet ou na loja física? }\end{array}$ & $\begin{array}{l}\text { "Preço da roupa e } \\
\text { a qualidade" }\end{array}$ & $\begin{array}{l}\text { "Estilo da roupa, } \\
\text { valor do frete, } \\
\text { forma de } \\
\text { pagamento" }\end{array}$ & $\begin{array}{l}\text { "Se é vantajoso } \\
\text { financeiramente e } \\
\text { se vou precisar" }\end{array}$ & $\begin{array}{l}\text { "Se preciso e se } \\
\text { está dentro do meu } \\
\text { orçamento" }\end{array}$ & $\begin{array}{l}\text { "Se gosto da roupa, } \\
\text { do modelo, se o } \\
\text { preço é justo" }\end{array}$ & $\begin{array}{l}\text { "Minha condição } \\
\text { financeira, valor } \\
\text { da fatura do } \\
\text { cartão de crédito } \\
\text { do próximo mês e } \\
\text { forma de } \\
\text { pagamento" }\end{array}$ \\
\hline $\begin{array}{l}\text { 09. Quando você fica insatisfeito com uma compra, utiliza a } \\
\text { internet para expor sua insatisfação? }\end{array}$ & $\begin{array}{l}\text { "Não, mas deixo } \\
\text { de comprar na } \\
\text { loja" }\end{array}$ & $\begin{array}{l}\text { "Nunca aconteceu } \\
\text { com compras de } \\
\text { roupas" }\end{array}$ & "Não, nunca" & $\begin{array}{l}\text { "Não, mas } \\
\text { reclamo com } \\
\text { pessoas próximas" }\end{array}$ & $\begin{array}{l}\text { "Algumas vezes } \\
\text { sim, depende do } \\
\text { quanto fico } \\
\text { insatisfeita" }\end{array}$ & "Não" \\
\hline $\begin{array}{l}\text { 10. O que você considera mais importante na hora de comprar } \\
\text { uma roupa? }\end{array}$ & "Qualidade" & $\begin{array}{l}\text { "Se o tecido } \\
\text { amassa" }\end{array}$ & $\begin{array}{l}\text { "Se fica bem em } \\
\text { mim" }\end{array}$ & $\begin{array}{l}\text { "Se preciso dela } \\
\text { naquele momento" }\end{array}$ & $\begin{array}{l}\text { "Se combina } \\
\text { comigo e se fica } \\
\text { bom em mim" }\end{array}$ & "Preço" \\
\hline $\begin{array}{l}\text { 11. Você considera um diferencial a empresa oferecer frete } \\
\text { grátis? }\end{array}$ & $\begin{array}{l}\text { "Sim, dou } \\
\text { preferência para } \\
\text { quem oferece" }\end{array}$ & $\begin{array}{l}\text { "Super! Costumo } \\
\text { procurar por lojas } \\
\text { que oferecem frete } \\
\text { grátis" }\end{array}$ & "Claro" & $\begin{array}{l}\text { "Com certeza, o } \\
\text { frete influencia no } \\
\text { preço final" }\end{array}$ & $\begin{array}{l}\text { "Considero super! } \\
\text { Mas se o prazo for } \\
\text { muito grande, } \\
\text { prefiro pagar para } \\
\text { chegar mais } \\
\text { rápido" }\end{array}$ & $\begin{array}{l}\text { "Certamente. } \\
\text { Filtro por lojas } \\
\text { que oferecem frete } \\
\text { grátis" }\end{array}$ \\
\hline $\begin{array}{l}\text { 12. Você tem o hábito de pesquisar tendências de roupas na } \\
\text { internet? }\end{array}$ & $\begin{array}{l}\text { "Não, compro } \\
\text { sempre o que } \\
\text { gosto" }\end{array}$ & $\begin{array}{l}\text { "Tenho. Pesquiso } \\
\text { pelo Pinterest e } \\
\text { Instagram" }\end{array}$ & "Sim" & "Raramente" & $\begin{array}{l}\text { "Não pesquiso, mas } \\
\text { sigo lojas que } \\
\text { postam e aí } \\
\text { acompanho" }\end{array}$ & $\begin{array}{l}\text { "Não, não sou } \\
\text { maníaca com } \\
\text { roupas" }\end{array}$ \\
\hline $\begin{array}{l}\text { 13. Você considera que a loja oferece roupas com estilo } \\
\text { diferenciado e inovador? Por quê? }\end{array}$ & $\begin{array}{l}\text { "As roupas são } \\
\text { mais casuais, não } \\
\text { considero } \\
\text { inovador" }\end{array}$ & $\begin{array}{l}\text { "As roupas são } \\
\text { lindas, mas são } \\
\text { casuais, tem estilo } \\
\text { diferenciado" }\end{array}$ & $\begin{array}{l}\text { "Sim, são só as } \\
\text { roupas da moda" }\end{array}$ & $\begin{array}{l}\text { "Não, são roupas } \\
\text { lindas, mas são } \\
\text { comuns" }\end{array}$ & $\begin{array}{l}\text { "São as roupas que } \\
\text { estão usando no } \\
\text { momento e estação, } \\
\text { mas não são } \\
\text { inovadoras" }\end{array}$ & $\begin{array}{l}\text { "Não, são roupas } \\
\text { casuais e bem } \\
\text { lindas" }\end{array}$ \\
\hline $\begin{array}{l}\text { 14. Em sua opinião, a infraestrutura da loja pode ser } \\
\text { considerada um aspecto positivo? (Considere facilidade de } \\
\text { estacionamento, espaço dentro da loja e área de banheiros / } \\
\text { provadores). }\end{array}$ & $\begin{array}{l}\text { "Sim, ter } \\
\text { estacionamento na } \\
\text { porta e um } \\
\text { provador grande } \\
\text { faz muita } \\
\text { diferença" }\end{array}$ & $\begin{array}{l}\text { "Com certeza! Um } \\
\text { ambiente } \\
\text { agradável e } \\
\text { prático faz toda } \\
\text { diferença na hora } \\
\text { de decidir ir à }\end{array}$ & $\begin{array}{l}\text { "Sim, considero } \\
\text { um aspecto } \\
\text { positivo" }\end{array}$ & $\begin{array}{l}\text { "Sim, } \\
\text { principalmente } \\
\text { estacionamento } \\
\text { gratuito" }\end{array}$ & $\begin{array}{l}\text { "Com certeza. Mas } \\
\text { não deixo de } \\
\text { comprar se gosto } \\
\text { das roupas, mas } \\
\text { não gosto da } \\
\text { infraestrutura". }\end{array}$ & $\begin{array}{l}\text { "Sim, com } \\
\text { certeza" }\end{array}$ \\
\hline
\end{tabular}

Simpósio de Tecnologia (Sitefa) - Fatec Sertãozinho - SP, v. 4, n. 1, p. 263-273, 2021. ISSN 2675-7540 


\begin{tabular}{|c|c|c|c|c|c|c|}
\hline & & loja" & & & & \\
\hline $\begin{array}{l}\text { 15. Ao sair para comprar uma roupa você já tem o modelo } \\
\text { previamente definido por já ter realizado pesquisas na internet? } \\
\text { 16. A mídia e as tendências de moda influenciam suas decisões e } \\
\text { preferências na compra de roupas? Por quê? }\end{array}$ & $\begin{array}{l}\text { "Depende da } \\
\text { situação. Algumas } \\
\text { vezes sim, outras } \\
\text { não" } \\
\text { "Não, pois não } \\
\text { acompanho } \\
\text { tendências" }\end{array}$ & $\begin{array}{l}\text { "Na maioria das } \\
\text { vezes, sim" } \\
\\
\text { "Algumas vezes } \\
\text { sim, outras não. } \\
\text { Mas gosto de saber } \\
\text { o que estão } \\
\text { usando" }\end{array}$ & $\begin{array}{l}\text { "Não, pois compro } \\
\text { sempre por } \\
\text { impulso" } \\
\text { "Claro, gosto de } \\
\text { estar atualizada } \\
\text { com a moda" }\end{array}$ & $\begin{array}{l}\text { "Sim, sempre sei o } \\
\text { quero" } \\
\text { "Não, não ligo } \\
\text { para a moda. } \\
\text { Apenas o que eu } \\
\text { gosto" }\end{array}$ & $\begin{array}{l}\text { "Depende, algumas } \\
\text { vezes sim e outras } \\
\text { não" } \\
\text { "Se eu gosto da } \\
\text { tendência sim, } \\
\text { acompanho o que } \\
\text { está sendo usado" }\end{array}$ & $\begin{array}{l}\text { "Não, no máximo } \\
\text { uma cor. Modelos } \\
\text { nunca" } \\
\text { "Não" }\end{array}$ \\
\hline $\begin{array}{l}\text { 17. Em sua opinião, a loja deveria oferecer algum outro serviço, } \\
\text { do qual você sente falta? Qual seria? }\end{array}$ & $\begin{array}{l}\text { "Não, sou } \\
\text { satisfeita com os } \\
\text { serviços } \\
\text { oferecidos" }\end{array}$ & $\begin{array}{l}\text { "Ficar aberta até } \\
\text { umas } 20 "\end{array}$ & $\begin{array}{l}\text { "Melhor o } \\
\text { atendimento e } \\
\text { oferecer acessórios } \\
\text { mais bonitos" }\end{array}$ & $\begin{array}{l}\text { "Melhoraro } \\
\text { atendimento" }\end{array}$ & $\begin{array}{l}\text { "Sapatos. Ajuda } \\
\text { muito sair com o } \\
\text { look completo da } \\
\text { loja" }\end{array}$ & $\begin{array}{l}\text { "Não. Mas } \\
\text { poderia ser mais } \\
\text { barata" }\end{array}$ \\
\hline $\begin{array}{l}\text { 18. Quais atributos você considera ao buscar uma loja de } \\
\text { roupas? }\end{array}$ & $\begin{array}{l}\text { "Qualidade, preço, } \\
\text { atendimento, } \\
\text { localização" }\end{array}$ & $\begin{array}{l}\text { "Atendimento, } \\
\text { forma de } \\
\text { pagamento e } \\
\text { qualidade" }\end{array}$ & $\begin{array}{l}\text { "Boa qualidade, } \\
\text { baixo preço e ter } \\
\text { liberdade de } \\
\text { experimentar sem } \\
\text { insistência" }\end{array}$ & $\begin{array}{l}\text { "Se tem o que } \\
\text { preciso com preço } \\
\text { bom" }\end{array}$ & $\begin{array}{l}\text { "Roupas bonitas, } \\
\text { bom atendimento, } \\
\text { prazo de entrega" }\end{array}$ & $\begin{array}{l}\text { "Preço, } \\
\text { qualidade, forma } \\
\text { de pagamento e } \\
\text { facilidade de } \\
\text { acesso" }\end{array}$ \\
\hline $\begin{array}{l}\text { 19. Você migrou } 100 \% \text { de suas compras para a internet, ou } \\
\text { continua comprando na loja física? }\end{array}$ & $\begin{array}{l}\text { "Não, ainda } \\
\text { compro muito em } \\
\text { loja física" }\end{array}$ & $\begin{array}{l}\text { "Não e acho que } \\
\text { não vou migrar. } \\
\text { Gosto de comprar } \\
\text { nos dois canais" }\end{array}$ & $\begin{array}{l}\text { "Não, compro } \\
\text { muito nas lojas } \\
\text { físicas" }\end{array}$ & $\begin{array}{l}\text { "Continuo } \\
\text { comprando na loja. } \\
\text { Compro aonde for } \\
\text { mais vantajoso" }\end{array}$ & $\begin{array}{l}\text { "Compro meio a } \\
\text { meio. Gosto muito } \\
\text { dos dois canais de } \\
\text { venda" }\end{array}$ & $\begin{array}{l}\text { "Tirando roupas, o } \\
\text { restante compro } \\
\text { muito pela } \\
\text { internet" }\end{array}$ \\
\hline
\end{tabular}

Fonte: elaborado pelos autores (2021) 


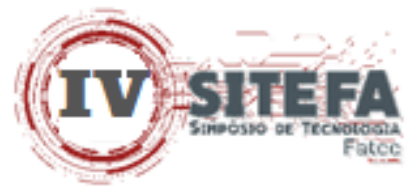

\subsection{Análise Geral do Quadro 1}

Ao estudar o processo decisório de compra do consumidor, é possível observar que existem vários fatores que influenciam a decisão final. Desta forma, este estudo consistiu em responder a seguinte pergunta: "Quais os principais atributos analisados pelas mulheres aos buscarem uma loja de roupas casuais?"

Apesar da grande influência das redes sociais e do meio digital, as clientes entrevistadas demonstraram que seguem perfis de moda, de lojas, gostam de roupas, mas ainda assim não se desvincularam das compras de roupas nas lojas físicas. Em alguns casos, roupas são os únicos itens que elas ainda não compram pela internet.

$\mathrm{Na}$ maioria das respostas, as compras de roupas e acessórios acontecem por impulso e muitas vezes as consumidoras não vão às compras com um modelo pré-definido. A escolha é feita na hora e são levadas as mais variadas peças, como blusas, calças, shorts, acessórios, o que mostra a importância de estar presente e com portfólio que agrade os gostos do consumidor e acompanhar as redes sociais e o que está acontecendo na internet, pois a maioria também respondeu que segue muitos perfis, apesar de não realizar interações e, também, não publicar quando ficam insatisfeitas com alguma compra.

Quando perguntadas sobre as vantagens e desvantagens de compras pela internet, a maioria disse que a comodidade de poder comprar em casa e a forma de pagamento que costumam ser melhores são muito bem-vistas, além do fato de o frete grátis ser muito importante e um grande fator de decisão, mas que o fato de não poder pegar, experimentar e ver o material da roupa é não satisfatório. Em relação à loja física, a vantagem é poder experimentar e entender se realmente gostou da peça com ela em mãos, mas as formas de pagamento são piores e tem o tempo gasto e o deslocamento até a loja que são tidos como desvantagens.

Mesmo com as desvantagens apontadas sobre a loja física, nota-se a importância de ainda ter um local para as compras, principalmente se não tiver clientes fiéis, uma vez que as respostas foram claras quanto continuar comprando pela internet caso a loja física feche, mas só se já conhecer e confiar na loja. E, também, porque um ponto levado em consideração pelas consumidoras foi sobre ver um modelo que gosta pela internet e ir ao local físico para experimentar e finalizar/ concluir a compra. Mas não é só ter um local físico, pela opinião das entrevistadas, a estrutura como localização, disponibilidade de estacionamento, provadores bons e um espaço agradável são levados em consideração.

Sobre o que as consumidoras consideram mais importante na hora de comprar uma roupa, itens como preço, qualidade e se precisam da peça naquele momento são levados em consideração. Preço e qualidade também foram citados nos atributos que elas consideram para escolher uma loja. Elas também consideram o atendimento, forma de pagamento e liberdade de escolha importante.

Em relação às perguntas específicas da loja, as consumidoras gostam muito do estilo de roupa oferecido e as consideram lindas, mas não inovadoras e diferenciadas. Um estilo mais básico e casual. As consumidoras conheceram a loja por indicação de familiares, amigos e por ser próximo de casa, comum em cidades do interior que não é muito grande e que as pessoas se conhecem em sua maioria. 


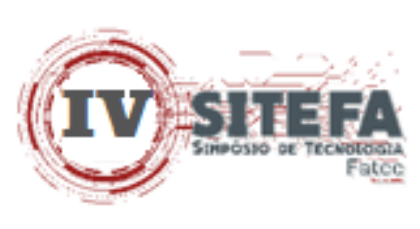

Também foram citados alguns pontos de melhoria, como o atendimento que não é satisfatório para algumas consumidoras e o horário de funcionamento, que por ser no horário comercial ( $08 \mathrm{~h}$ às $18 \mathrm{~h}$ ) algumas consumidoras só consegue ir ao final de semana. Estender até às $20 \mathrm{~h}$ seria um ponto importante para algumas que querem passar após o horário de trabalho e não podem ou não querem esperar alguns dias para adquirir a peça necessária.

\section{CONSIDERAÇÕES FINAIS}

Resgatando-se o objetivo central da presente pesquisa tem-se: compreender o comportamento de compra de consumidoras de uma loja de roupas casuais, localizada no interior do estado de Minas Gerais, assim como investigar o nível de satisfação das clientes com a loja (localização, infraestrutura, atendimento etc.).

Assim sendo, constatou-se que as redes sociais estão cada vez mais presentes no dia a dia das consumidoras e influenciando comportamentos de compra e consumo, e estar presente e acompanhar as tendências de moda e interações se torna cada vez mais importante. Apesar das consumidoras não seguirem à risca a moda e o que está em alta, elas acompanham os perfis de lojas e sabem o que está acontecendo (tendências, lançamentos etc.).

Ter uma rede social atualizada com as novidades, oferecer benefícios como frete grátis, melhores formas de pagamento e a comodidade de comprar onde estiver em poucos minutos tem sido fatores decisórios para as compras via Internet, mas a presença da loja física com uma boa infraestrutura, localização, ambiente agradável e bom atendimento ainda é um fator muito relevante e levado em consideração.

Na maioria das respostas, as compras de roupas e acessórios acontecem por impulso e muitas vezes as consumidoras não vão às compras com um modelo pré-definido. Preço e qualidade das roupas também foram citados pelas entrevistadas como atributos que elas consideram relevantes para escolher uma loja. Elas também consideram importantes: o atendimento, a forma de pagamento e a liberdade de escolha.

Em relação às perguntas específicas sobre a loja, as consumidoras gostam muito do estilo de roupa oferecido e as consideram lindas, mas não inovadoras e diferenciadas; um estilo mais básico e casual. Com o presente trabalho foi possível observar a importância de conhecer o comportamento do consumidor em todos seus aspectos, sobre o que é fundamental para que suas necessidades e seus desejos sejam atendidos e sanados, satisfazendo-o e procurando sempre a fidelidade e lealdade dele.

\section{REFERÊNCIAS}

CHURCHILL, Gilbert. Marketing: Criando valor para os clientes. SP: Saraiva, 2000.

COLLIS, Jill; HUSSEY, Roger. Pesquisa em Administração: um guia prático para alunos de graduação e pós-graduação. 2 ed. Porto Alegre: Bookman, 2005.

ENGEL, J. F.; BLACKWEEL, R. P.; MINARD, P.W. Comportamento do consumidor. 8. ed. Rio de Janeiro: LTC, 2000.

GIL, Antônio Carlos. Métodos e Técnicas de Pesquisa Social. 6. ed. São Paulo: Atlas, 2008. 
KOTLER, Philip; KELLER, Kevin Lane. Administração de Marketing. 12. ed. SP: Pearson Prentice Hall, 2006.

MALHOTRA, N. K. Pesquisa de marketing: uma orientação aplicada. 3. ed. Porto Alegre: Bookman, 2001.

MOWEN, John C.; MINOR, Michael S. Comportamento do Consumidor. São Paulo: Prentice-hall, 2003.

SANTOS, José Luiz dos. O que é Cultura. Coleção Primeiros Passos. São Paulo: Editora Brasiliense, 2006.

SCHIFFMAN, Leon G.; KANUK, Leslie Lazar. Comportamento do consumidor. Rio de Janeiro: LTC, 2000.

SHETH, Jagdis N., MITTAL, Banwari.; NEWMAN, Bruce I. Comportamento do cliente. São Paulo: Atlas, 2001.

SOLOMON, Michael R. O comportamento do consumidor: comprando, possuindo e sendo. 9. ed. Porto Alegre: Bookman, 2011.

VERGARA, S. C. Projetos e relatórios de pesquisa em administração. 4 ed. São Paulo: Atlas, 2003. 